\title{
Good HIT and bad HIT
}

\section{First and foremost, do no harm. Second, do some good}

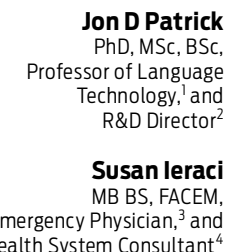

1 School of Information Technologies,

University of Sydney,

Sydney, NSW.

2 Innovative Clinical Information

Management Systems,

Sydney, NSW.

3 Bankstown Hospital,

Sydney, NSW.

4 SI-napse

Sydney, NSW.

jonpat@it.usyd.edu.au

doi: 10.5694/mjal2.11350

Editorial p 178 Research p 201 ne of the key issues for high-volume, high-risk workplaces like hospital emergency departments (EDs) is the struggle of conflicting aims. While hospital managers need information systems for data collection and storage, clinicians need efficient clinical documentation, data retrieval and order-entry systems that save time rather than steal it from the patient. The work of clinicians is aided by reliable data but impaired by the delays of real-time input, difficult system navigation, suboptimal presentation of information, and other problems in the user experience of health information technology (HIT) ${ }^{1}$

Mohan and colleagues' study of the impact of an electronic medical record information system on ED performance had some limitations. ${ }^{2}$ It was retrospective and unable to control for all confounders, and therefore could only show a correlation with ED delays, not causation. However, the premise for the study delivers an important message the work required to use the information system was perceived by the ED staff to directly conflict with time spent with patients.

Another study has shown that the same electronic medical record information system is perceived to have had a negative impact on the care of patients, as well as the productivity and morale of staff, in six EDs in New South Wales. ${ }^{3}$ The need to be hypervigilant about the accuracy of the information supplied by the electronic health record compounds an already stressful clinical environment, which in turn leads to resentment towards the technology and the people who have imposed it. This makes it "bad" HIT. Unless this is corrected, HIT efforts will overuse precious health care resources, will be unlikely to achieve claimed benefits for many years to come, and may actually cause harm. ${ }^{4,5}$

The large HIT corporations produce a type of technology that is best categorised as enterprise resource planning (ERP), which has its roots in the manufacturing industry. It is based on the idea that all processes within an organisation can be standardised, and that all processes of the same type should have their information modelled and processed in the same manner. If this high degree of standardisation were considered the best way to process and model information derived from clinical activity, then ERP would be a favoured technology to adopt, as has happened in many places.

However, there is an alternative, almost contradictory, perspective on the nature of clinical work: that it is nondeterministic and performed by a group of diverse staff working in an ecologically stable network of people that has to respond to diverse medical needs and diseases. The ecology model accommodates staff joining and leaving the process, with differing needs emerging at different times, so that the other individuals in the network have to adapt and modify their behaviour and improvise in an unpredictable manner. Amid all this variability is the ever-demanding imperative to improve the processes of care and attention to the patient, while also increasing staff productivity. ${ }^{6}$

Where the ERP model has been imposed in the clinical setting, staff may be coerced into an approach to their work that is at odds with established best practices. This could only be considered "good" HIT if it brought greater staff productivity with at least no loss (and, preferably, improvement) of patient safety and services and staff morale.

It is not enough just to identify problems: effort must be invested in transforming bad HIT into good HIT. This process must identify and optimise all the operative factors: human behaviour, system design, equipment performance, skills of the IT participants, and the operational policy framework. ${ }^{7}$ Good HIT should include clinician control of the interface design for content, dataflow and workflow. It includes the ability to change the system in real time, and it incorporates inbuilt data analytical capability, natural language processing, and native interoperability and clinical coding. ${ }^{8}$ Finally, there must be an appropriate opportunity to test systems for useability, effectiveness and suitability before their release.

There must be a move away from standardised processing models and towards improving the user experience in the clinical setting. Clinicians should not have to shoehorn their activity into predefined, externally imposed work processes that do not reflect actual activity and will not improve efficiency. A true patient-focused system aligns all its components towards the same aim. Like a good clinician, good HIT does no harm — to patients or staff.

Acknowledgements: We would like to express our appreciation for the advice provided by our colleagues Ross Koppel, Scot Silverstein and Scott Montieth.

Competing interests: Jon Patrick is the R\&D Director for two companies providing services to health organisations. Susan leraci performs clinical care and health system consultation in public hospital emergency departments.

Provenance: Commissioned; externally peer reviewed.

1 Committee on Patient Safety and Health Information Technology, Institute of Medicine. Health IT and patient safety: building safer systems for better care. Washington, DC: The National Academies Press, 2012.

2 Mohan MK, Bishop RO, Mallows JL. Effect of an electronic medical record information system on emergency department performance. Med J Aust 2013; 198: 201-204.

3 Patrick J. A study of a health enterprise information system. Sydney: School of Information Technologies, University of Sydney, 2011. (Technical report TR673.) http://sydney.edu.au/engineering/it/ hitru/index.php?option= com_content\&task=view\&id=91\&ltemid=146 (accessed Feb 2013).

4 Silverstein S. Why the overambitious, cavalier approaches of the healthcare IT industry are harmful to health. Health Care Renewal [blog] 2011; Mar 14. http://hcrenewal.blogspot.com.au/2011/03/why-current-nature-ofhealthcare-it.html (accessed Sep 2012).

5 Coiera EW, Kidd MR, Haikerwal MC. A call for national e-health clinical safety governance [editorial]. Med J Aust 2012; 196: 430-431.

6 Silverstein S. Critical thinking on evidence-based medicine and better clinical outcomes: improving health IT as the first step [abstract]. Proceedings of HIC 2012; 31 Jul - 2 Aug; Sydney, NSW.

7 Leape LL, Berwick DM. Five years after To Err Is Human: what have we learned? JAMA 2005; 293: 2384-2390.

8 Patrick JD, Budd P. Ockham's razor of design: an heuristic for guiding design and development of a clinical information systems generator. Proceedings of the lst ACM International Health Informatics Symposium; 2010 Nov 11-12; Arlington, Va. New York: ACM, 2010: 18-27. http://portal.acm.org/citation.cfm? id=1882998\&CFID=116605072\&CFTOKEN=43603995 (accessed Aug 2012). 